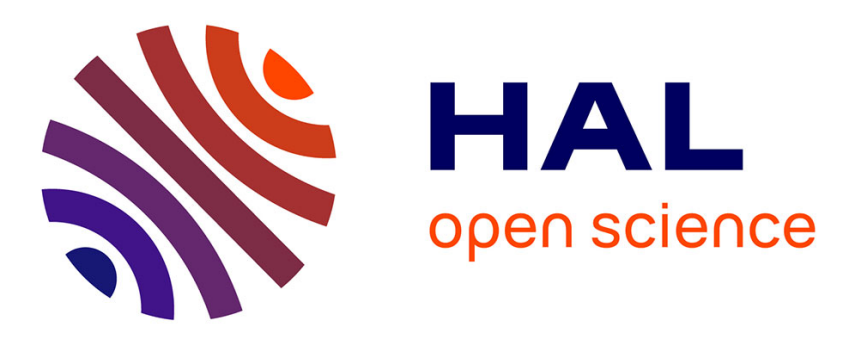

\title{
High clonality in Acropora palmata and Acropora cervicornis populations of Guadeloupe, French Lesser Antilles
}

A Japaud, C Bouchon, J-L Manceau, Cécile Fauvelot

\section{- To cite this version:}

A Japaud, C Bouchon, J-L Manceau, Cécile Fauvelot. High clonality in Acropora palmata and Acropora cervicornis populations of Guadeloupe, French Lesser Antilles. Marine and Freshwater Research, 2015, 66, 10.1071/mf14181 . ird-03044178

\author{
HAL Id: ird-03044178 \\ https://hal.ird.fr/ird-03044178
}

Submitted on 7 Dec 2020

HAL is a multi-disciplinary open access archive for the deposit and dissemination of scientific research documents, whether they are published or not. The documents may come from teaching and research institutions in France or abroad, or from public or private research centers.
L'archive ouverte pluridisciplinaire HAL, est destinée au dépôt et à la diffusion de documents scientifiques de niveau recherche, publiés ou non, émanant des établissements d'enseignement et de recherche français ou étrangers, des laboratoires publics ou privés. 


\title{
High clonality in Acropora palmata and Acropora cervicornis populations of Guadeloupe, French Lesser Antilles
}

\author{
A. Japaud ${ }^{\mathrm{A}}$, C. Bouchon ${ }^{\mathrm{A}}$, J.-L. Manceau ${ }^{\mathrm{A}}$ and C. Fauvelot ${ }^{\mathrm{B}, \mathrm{C}}$ \\ A UMR 7208 BOREA, LabEx CORAIL, Université des Antilles et de la Guyane, BP 592, \\ 97159 Pointe-à-Pitre, Guadeloupe. \\ BUMR 9220 ENTROPIE, LabEx CORAIL, Centre IRD de Nouméa, 101 Promenade Roger Laroque, \\ BPA5, 98848 Nouméa, New Caledonia. \\ ${ }^{\mathrm{C}}$ Corresponding author. Email: cecile.fauvelot@ird.fr
}

\begin{abstract}
Since the 1980s, population densities of Acroporidae have dramatically declined in the Caribbean Sea. Quantitative censuses of Acroporidae provide information on the number of colonies (i.e. ramets), but not on the number of genetically distinct individuals (i.e. genets). In this context, the aim of our study was to provide an overview of the genetic status of Acropora populations in Guadeloupe by examining the genotypic richness of Acropora palmata and Acropora cervicornis. Using 14 microsatellite loci, we found extremely low genotypic richness for both species from Caye-à-Dupont reef (i.e. 0.125 for $A$. palmata and nearly zero for A. cervicornis). Because genetic diversity contributes to the ability of organisms to evolve and adapt to new environmental conditions, our results are alarming in the context of ongoing global warming as long periods of clonal growth without sexual recruitment may lead to the extinction of these populations.
\end{abstract}

Additional keywords: genotypic richness, Acroporidae, microsatellites, Caribbean Sea.

Received 27 June 2014, accepted 5 November 2014, published online 19 March 2015

\section{Introduction}

Stony corals of the Acroporidae (Class Anthozoa, Order Scleractinia) belong to the most important reef-builders, providing complex shelter for fish and numerous other species (Gladfelter 1982; Bruckner 2002). In the Caribbean Sea, the Acroporidae is represented by two species, Acropora palmata (Lamarck, 1816) (elkhorn coral) and Acropora cervicornis (Lamarck, 1816) (staghorn coral). Acropora prolifera (Lamarck, 1816) is a firstgeneration hybrid of the two species (Van Oppen et al. 2000; Vollmer and Palumbi 2002). Since the 1980s, populations of A. palmata and A. cervicornis have declined dramatically in Guadeloupe and more generally in the Caribbean Sea (over $80 \%$ of population reduction during the past 30 years), likely due to the combined effects of hurricanes, diseases, climate change and human-related factors (Precht et al. 2002; Williams and Miller 2005; Miller et al. 2009). Caribbean acroporid species have been classified as 'critically endangered' since 2008 by the International Union for Conservation of Nature, regulated by the US Endangered Species Act and listed on the Washington Convention (CITES, Appendix II).

Acroporid species have two reproductive modes: a sexual one with gamete production, which increases the genetic variability of the populations, and an asexual mode, called fragmentation or clonal reproduction, which produces genetically identical colonies or clones. Therefore, whereas quantitative censuses of acroporid densities report on the number of ramets (i.e. coral colonies), the number of genets (i.e. genetically distinct individuals) usually remains unknown despite its importance. Indeed, clonal reproduction reduces genotypic diversity which may, as a result, lead to increased susceptibility to environmental instability (Booth and Grime 2003; Reusch et al. 2005). Furthermore, remnant populations may become sexually extinct after prolonged clonal growth and the absence of immigration from other populations (ecologically driven sexual extinction) (Honnay and Bossuyt 2005). Therefore, knowledge of genetic and genotypic diversity patterns is thus critical in declining populations in which recruitment by sexual reproduction is thought to be limited (Baums et al. 2006). In this context, the aim of our study was to provide an overview of the genetic status of $A$. palmata and A. cervicornis populations in Guadeloupe by examining the proportion of genets versus the proportion of ramets in these two species.

\section{Materials and methods}

Location

In order to avoid confounding environmental factors that may hamper direct comparison of genetic diversity among species, surveys were conducted in early 2011 on various promising and easily accessible reefs of Guadeloupe, French Antilles, to 
select possible study sites that offered dense populations of both species. Although sparse Acropora palmata colonies were found on almost all coral reefs surveyed around the island, dense populations were rarely observed. Moreover, very few colonies of $A$. cervicornis were encountered on Guadeloupean reefs. We found a unique reef with dense populations of both $A$. palmata and A. cervicornis, Caye-à-Dupont (Fig. 1), which was then selected for our study. This site is located on an isolated reef of the 'Petit Cul-de-Sac Marin' lagoon in front of the city of Goyave, Guadeloupe. The colonies of A. cervicornis $\left(16^{\circ} 09^{\prime} 27.07^{\prime \prime} \mathrm{N}, 61^{\circ} 32^{\prime} 42.36^{\prime \prime} \mathrm{W}\right)$ are located on the reef flat, between 2 and $3 \mathrm{~m}$ deep, whereas the colonies of $A$. palmata $\left(16^{\circ} 09^{\prime} 25.60^{\prime \prime} \mathrm{N}, 61^{\circ} 32^{\prime} 33.18^{\prime \prime} \mathrm{W}\right)$ are located on the fore reef zone at $\sim 2 \mathrm{~m}$ deep.

\section{Sampling}

For each species, a central colony of the respective population was designated as the landmark and georeferenced. Each other colony was thereafter geographically located from this first one, by measuring the distance separating each colony from its neighbour and recording the bearing with a compass. All colonies within a circle of $30 \mathrm{~m}$ radius from the central colony were then identified, labelled and geolocated. A coral fragment was cut from each colony and placed into a Falcon tube containing 70\% ethanol. In total, $80 \mathrm{~A}$. palmata colonies and 80 of $\mathrm{A}$. cervicornis were sampled in December 2011.

\section{Molecular analysis}

Genomic DNA was isolated from 5-10 polyps per individual colony using a DNA Purification Kit (formerly Gentra Puregene, Qiagen, Germantown, MD, USA) following the manufacturer's protocol. Forward primers of A. palmata specific microsatellite loci (Baums et al. 2005, 2009) were labelled with ABI fluorescent dyes and 14 loci were successfully amplified into two multiplex PCRs as follows: Multiplex1: 0007/NED, 0166/PET, 0192/6-FAM, 0207/VIC, 1195/PET, 2637/VIC, and 5047/NED; Multiplex2: 0181/NED, 0182/PET, 0513/6-FAM, 0585/VIC, 1490/PET, 6212/NED and 9253/VIC Multiplex PCR reactions were conducted in a thermocycler (GeneAmp PCR System 2700, Applied Biosystems, Foster City, CA, USA) in a final volume of $10 \mu \mathrm{L}$ using the Type-it Microsatellite PCR Kit (Qiagen) according to the manufacturer's protocol, and using an annealing temperature of 57 and $55^{\circ} \mathrm{C}$ for Multiplex 1 and 2 respectively. Amplified fragments were sent to Genoscreen (Lille, France), where they were resolved on an ABI 3730XL sequencer along with a GeneScan LIZ-500 internal size standard (Applied Biosystems). GENEMAPPER 5.0 software (Applied Biosystems) was used to genotype all screened individuals.

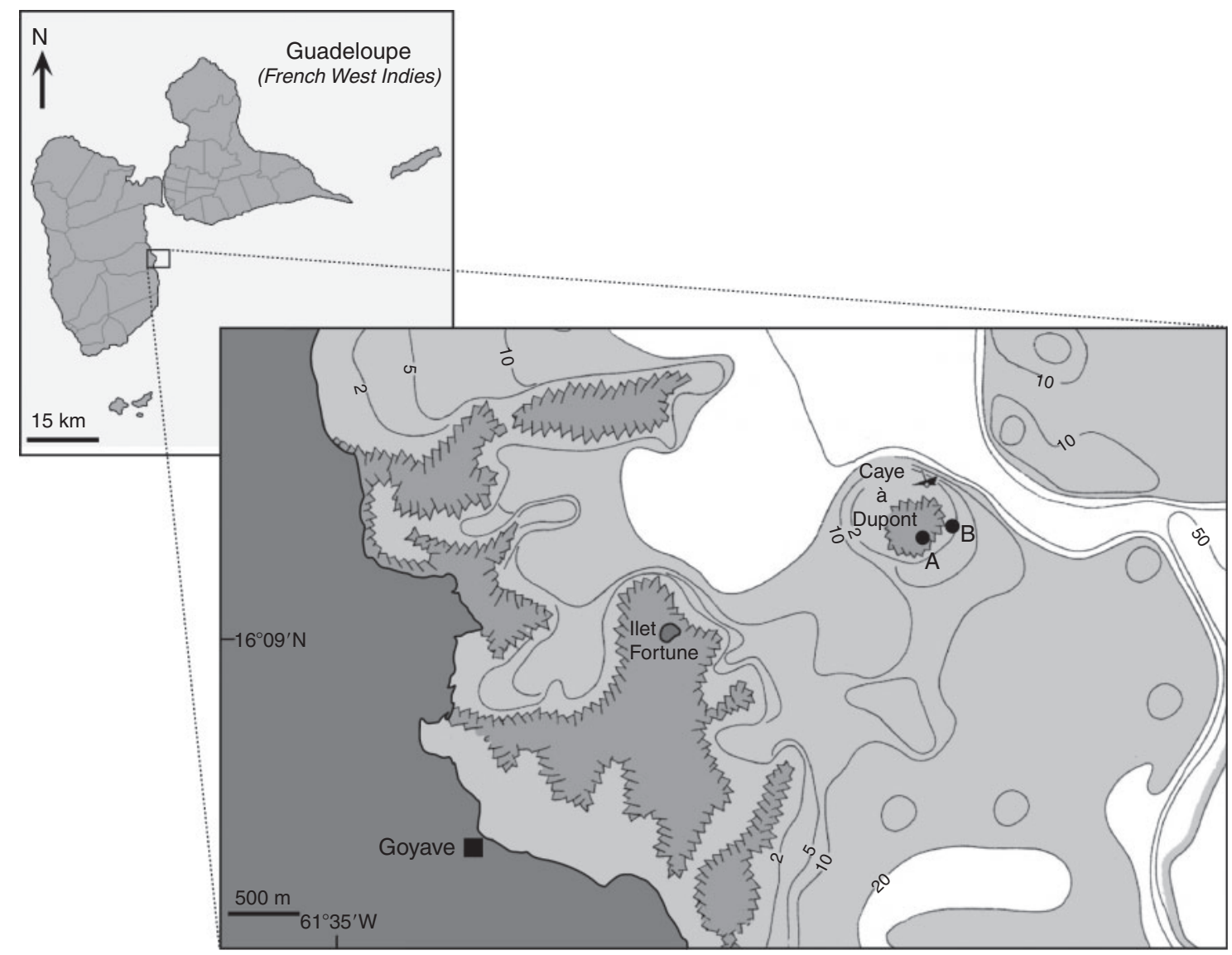

Fig. 1. Location of the Caye-à-Dupont study site and sampled Acropora populations in Guadeloupe. (a) A. cervicornis; (b) A. palmata. 


\section{Data analysis}

In order to identify the number of distinct multilocus genotypes (referred to hereafter as 'MLG') among each colony (referred hereafter as 'ramets'), for each species dataset, we used GENOTYPE (Meirmans and van Tienderen 2004), which allows the inclusion of three-allele genotypes. Indeed, in both species, several samples showed three fluorescent peaks of comparable intensity and shape at some loci. These third allele peaks were clearly distinguishable from potential stutter peaks because (1) the three peaks were comparable, so that we could not choose two alleles among the three peaks, and (2) stutter peaks were not present in comparable two-allele chromatograms, likely because of the use of loci with trinucleotiderepeat motifs (Baums et al. 2005, 2009). Additionally, we found a gap in the distribution of pairwise allele differences among MLGs (2-13 alleles difference). Therefore, MLGs appearing 1 or 2 alleles different from each other, as well as MLGs presenting a third additional allele peak at one or two loci, were interpreted as somatic mutants of the same MLG (Van Oppen et al. 2011) and were therefore coded as belonging to the same multilocus lineage (referred to hereafter as 'MLL'). GMCONVERT (Faircloth 2006) was used to convert an exported GENEMAPPER table of genotypes into a GENEPOP (Raymond and Rousset 1995) input file. Genotypic linkage disequilibria, number of alleles per locus, number of genotypes per locus, expected and observed heterozygosity, null allele frequencies and fixation index estimate $\left(F_{\text {IS }}\right)$ (Weir and Cockerham 1984) were estimated using the online GENEPOP 4.2 (http://genepop.curtin.edu.au/, accessed 14 January 2015). Significant departures from Hardy-Weinberg equilibrium were tested using the exact test implemented in GENEPOP with specified Markov Chain parameters as several 1000 for the dememorisation, followed by 1000 batches of 1000 iterations per batch.

\section{Results and discussion}

Somatic mutations were observed in both species, at equivalent rates $(14 \%$ of sampled ramets presented somatic mutations for A. palmata and $15 \%$ for $A$. cervicornis) (Table 1).

Among the $80 \mathrm{~A}$. palmata colonies sampled and analysed, 10 MLLs were found (Table 1; Fig. 2a). Each MLL was represented by several ramets (ranging from 2 to 34 ).

For A. cervicornis, a single MLL was encountered among the 80 sampled and analysed colonies (Table 1; Fig. $2 b$ ) so that all sampled colonies were interpreted to be clones. This MLL was then composed of 80 individual ramets over an area of $2826 \mathrm{~m}^{2}$

Between these two Caye-à-Dupont populations of identical sample size ( $n=80$ per species), the number of identified MLLs was then different by a factor of ten. Estimates of genotypic richness ranged from 0.0125 for $A$. cervicornis population to 0.125 for nearby $A$. palmata population (Table 1 ).

For A. palmata, only one representative of each MLL was kept for the following analyses. The 14 analysed microsatellite

Table 1. Clonal diversity for each Acropora population $\mathrm{N}$, number of ramets; $\mathrm{N}_{\mathrm{MLG}}$, number of multilocus genotypes; $\mathrm{N}_{\mathrm{MLL}}$, number of multilocus lineages; $\mathrm{N}_{\mathrm{MLL}} / \mathrm{N}$, genotypic richness; Somatic mutants: percentage of sampled ramets that present somatic mutations;

Maximum distance: maximum distance $(\mathrm{m})$ between clones

\begin{tabular}{lcc}
\hline & Acropora palmata & Acropora cervicornis \\
\hline $\mathrm{N}$ & 80 & 80 \\
$\mathrm{~N}_{\mathrm{MLG}}$ & 20 & 5 \\
$\mathrm{~N}_{\mathrm{MLL}}$ & 10 & 1 \\
$\mathrm{~N}_{\mathrm{MLL}} / \mathrm{N}$ & 0.125 & 0.0125 \\
Somatic mutants (\%) & 13.75 & 15 \\
Maximum distance (m) & $\geq 25$ & $\geq 60$ \\
\hline
\end{tabular}

(a)

0

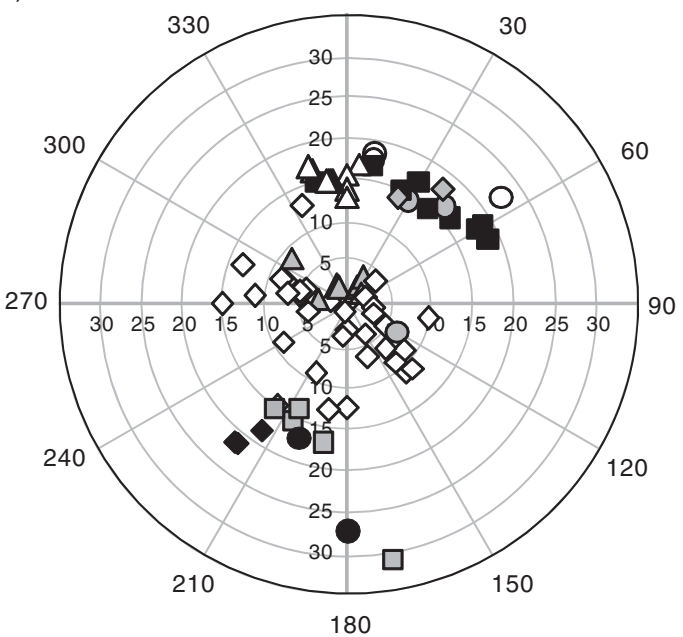

(b)

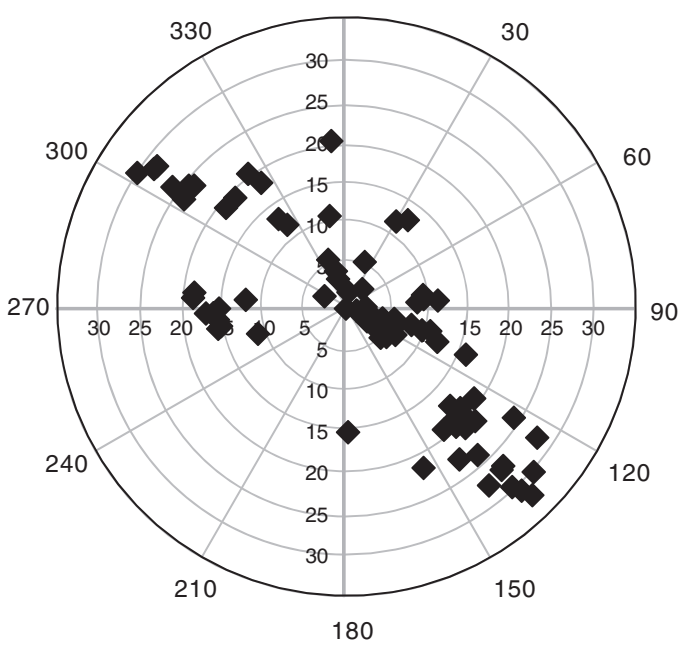

Fig. 2. Representative polar plot maps of genotypic lineage diversity within (a) Acropora palmata and (b) Acropora cervicornis populations. Each symbol represents a sampled ramet, with common symbol and colour for genetically identical multilocus lineages (MLL). 
Table 2. Genetic diversity at 14 microsatellite loci for Acropora palmata

$\mathrm{N}_{\mathrm{MLL}}$, number of multilocus lineages; $\mathrm{N}_{\mathrm{g}}$, number of single-locus genotypes; $\mathrm{N}_{\mathrm{a}}$, number of alleles; $\mathrm{H}_{\mathrm{E}}$, expected heterozygosity; $\mathrm{H}_{\mathrm{O}}$, observed heterozygosity; $P$, probability of deviation from Hardy-Weinberg expectations by exact tests (n.s., non-significant); $F_{\text {IS }}$, Weir and Cockerham's (1984) estimate fixation index; r, null allele frequency. Without clones and somatic mutations, $\mathrm{N}_{\mathrm{MLL}}=10$

\begin{tabular}{lcccccrc}
\hline Locus & $\mathrm{N}_{\mathrm{g}}$ & $\mathrm{N}_{\mathrm{a}}$ & $\mathrm{H}_{\mathrm{E}}$ & $\mathrm{H}_{\mathrm{O}}$ & $P$ & \multicolumn{1}{c}{$F_{\mathrm{IS}}$} & $\mathrm{r}$ \\
\hline 0007 & 9 & 7 & 0.88 & 0.80 & n.s. & 0.10 & 0.12 \\
1195 & 5 & 5 & 0.62 & 0.50 & n.s. & 0.20 & 0.08 \\
0166 & 9 & 11 & 0.91 & 0.90 & n.s. & 0.01 & 0.04 \\
0192 & 8 & 8 & 0.79 & 0.70 & n.s. & 0.12 & 0.13 \\
0207 & 9 & 9 & 0.87 & 0.80 & n.s. & 0.08 & 0.07 \\
2637 & 9 & 7 & 0.82 & 0.80 & n.s. & 0.02 & 0.01 \\
5047 & 5 & 5 & 0.56 & 0.60 & n.s. & -0.08 & 0.00 \\
1490 & 5 & 3 & 0.64 & 0.50 & n.s. & 0.22 & 0.24 \\
0181 & 4 & 4 & 0.49 & 0.40 & n.s. & 0.19 & 0.29 \\
0182 & 8 & 9 & 0.83 & 0.70 & n.s. & 0.16 & 0.09 \\
0513 & 5 & 5 & 0.51 & 0.50 & n.s. & 0.01 & 0.00 \\
0585 & 7 & 5 & 0.67 & 0.70 & n.s. & -0.04 & 0.07 \\
6212 & 5 & 4 & 0.64 & 0.60 & n.s. & 0.07 & 0.20 \\
9253 & 6 & 5 & 0.72 & 0.80 & n.s. & -0.13 & 0.00 \\
Mean & - & 6.2 & 0.71 & 0.66 & - & 0.07 & - \\
\hline
\end{tabular}

loci were polymorphic and the number of alleles per locus ranged from 3 (in Apal1490) to 11 (in Apal166) (Table 2). Tests of genotypic linkage disequilibrium between loci within samples indicated no significant association of alleles (all $P>0.05$ ), confirming that all loci can be treated as independent markers. Estimated null allele frequencies ( $\mathrm{r}$ ) per sample ranged from $<0.0001$ (Apal5047 and Apal513) to 0.29 (Apal181) (Table 2). Observed heterozygosities ranged between 0.40 (Apal181) and 0.90 (Apal166) and expected heterozygosities ranged between 0.49 (Apal181) and 0.91 (Apal166) (Table 2). The estimate of multilocus observed heterozygosity was 0.66 and the estimate of multilocus expected heterozygosity was 0.71 (Table 2 ). Loci did not show significant deviations from Hardy-Weinberg expected genotype frequencies in all samples (Table 2). All estimates of $F_{\text {IS }}$ ranged from -0.08 (Apal5047) to 0.2241 (Apal1490) and the multilocus estimate of $F_{\text {IS }}$ was 0.07 (Table 2).

Acropora populations of Caye-à-Dupont reef present an analogy in terms of low observed genotypic richness (i.e. 0.125 for $A$. palmata and nearly 0 for $A$. cervicornis). These findings reveal that the maintenance of Acropora populations at this site is mostly asexual, and that sexual recruitment on this reef is limited for both species. Such estimates are weaker than genotypic richness estimates of A. palmata populations reported in the Caribbean by Baums et al. (2006) and Mège et al. (2014) (mean per reef $=0.5$ and 0.75 respectively). In particular, Guadeloupean A. palmata populations studied by Mège et al. (2014) show a much higher genotypic richness (0.96) than that for Caye-à-Dupont reported here (0.125). However, Mège et al. (2014) favoured a non-random, opportunistic sampling strategy to avoid over-representation of clones for the benefit of genetic structure analyses (Mège et al. 2014) whereas we sampled all colonies in a circle of 30-m radius to better assess the contribution of clonal reproduction in the studied population. Therefore, this large difference between estimates may be explained by the different sampling strategies, although Baums et al. (2006) did not observe such discrepancies while using randomised circle plots against opportunistic sampling.

Variations of asexual reproduction among sites at the province, the region or the reef scales are influenced by fragmentation efficiency and relative geoclimatic conditions (wave intensity, hurricane frequency and intensity, topography) (Coffroth and Lasker 1998; Baums et al. 2006). For example, swell is known to significantly affect the spatial distribution of coral populations, in particular clonal colonies derived from fragmentation. On the Caye-à-Dupont reef, the high capacity of the Acropora populations to reproduce asexually is induced by an active hydrodynamic mode (prevailing swell induced by trade winds from the east) and an efficient capacity for fragmentation. During high swells, waves break on the reef flat zone and the flat bottom prevents the dispersal of coral fragments and advantages their fixation nearby. In contrast, the Anse-Bertrand reef is positioned against a small cliff, and the A. palmata colonies studied were sampled at depths where they were growing in an encrusting fashion, likely limiting their ability to produce asexual recruits via fragmentation (Mège et al. 2014). Therefore, the choice of the sampling sites may further explain some of the discrepancy observed between our genotypic richness estimate for A. palmata from Caye-à-Dupont and those found in the other Guadeloupean localities studied by Mège et al. (2014).

The maximum distance between two identified clones of A. cervicornis was at least $60 \mathrm{~m}$ (i.e. the maximum distance between two sampled ramets), whereas it was $25 \mathrm{~m}$ for A. palmata (Table 1). These two estimated distances are minimum estimates, as they were calculated on the basis of sampled ramets within a circle of 30-m radius from a central colony, and not by considering all potential clones located outside this circle. The skeletal structure of $A$. cervicornis, more fragile than that of A. palmata, likely explains the better capacity for fragmentation of A. cervicornis (Bottjer 1980; Tunnicliffe 1981; Garcia Reyes and Schizas 2010). Thus, the clonal propagation of genets by fragmentation is higher for $A$. cervicornis than for A. palmata, as confirmed by the maximum distance among clones.

For $A$. palmata, the 10 MLLs found among the 80 ramets analysed suggest that, in spite of this population being mostly asexual, recruitment of coral larvae issued from sexual reproduction has occurred. On the contrary, the fact that the A. cervicornis population was monoclonal (i.e. a single MLL found) reveals a poor recruitment of new individuals from sexual reproduction. Because genetic diversity contributes to the ability of the organisms to evolve and adapt to new conditions, this result has profound implications. Indeed, it is known that some genets can be more resistant to environmental perturbations and therefore coral bleaching (Edmunds and Gates 2003). Moreover, the association of an absence of sexual recruitment and a strong clonal growth in a population over a long period may lead to an extinction of the population (Honnay and Bossuyt 2005). The results from this genetic characterisation of Acropora populations in Guadeloupe are therefore alarming in the context of ongoing global warming, especially for $A$. cervicornis. Even though Mège et al. (2014) found high genetic diversities in $A$. palmata populations and no genetic 
differentiation among $A$. palmata populations of the eastern Caribbean region (including Guadeloupe), genetic characterisation of additional Guadeloupean Acropora populations is now needed to estimate the general status of these species on the island and hopefully reveal the unique status of Caye-à-Dupont populations.

\section{Conclusion}

These Guadeloupean populations of Acropora palmata and Acropora cervicornis on Caye-à-Dupont reef both present extremely low genotypic richness levels, particularly the A. cervicornis population, which was found to be monoclonal (i.e. a single MLL was encountered among the 80 analysed colonies). These results suggest that the maintenance of these Acropora populations mostly relies on an asexual reproduction and that sexual recruitment on this reef is likely limited for both species. Because long periods of clonal growth without sexual recruitment may lead to the extinction of these populations, these preliminary results are alarming in the context of ongoing global warming for Guadeloupean Acropora populations, especially for A. cervicornis.

\section{Acknowledgements}

We gratefully thank Sébastien Cordonnier for his help in the field and the two anonymous referees for their valuable comments.

\section{References}

Baums, I. B., Hughes, C. R., and Hellberg, M. E. (2005). Mendelian microsatellite loci for the Caribbean coral Acropora palmata. Marine Ecology Progress Series 288, 115-127. doi:10.3354/MEPS288115

Baums, I. B., Miller, M. W., and Hellberg, M. E. (2006). Geographic variation in clonal structure in a reef-building Caribbean coral, Acropora palmata. Ecological Monographs 76, 503-519. doi:10.1890/0012-9615 (2006)076[0503:GVICSI]2.0.CO;2

Baums, I. B., Devlin-Durante, M. K., Brown, L., and Pinzón, J. H. (2009). Nine novel, polymorphic microsatellite markers for the study of threatened Caribbean acroporid corals. Molecular Ecology Resources 9 1155-1158. doi:10.1111/J.1755-0998.2009.02581.X

Booth, R. E., and Grime, J. P. (2003). Effects of genetic impoverishment on plant community diversity. Journal of Ecology 91, 721-730. doi:10.1046/J.1365-2745.2003.00804.X

Bottjer, D. J. (1980). Branching morphology of the reef coral Acropora cervicornis in different hydraulic regimes. Journal of Paleontology 54, 1102-1107.

Bruckner, A. W. (2002). Proceedings of the Caribbean Acropora Workshop: Potential Application of the US Endangered Species Act as a Conservation Strategy. NOAA Technical Memorandum NMFS-OPR-24, Silver Spring, MD, USA.

Coffroth, M. A., and Lasker, H. R. (1998). Population structure of a clonal gorgonian coral: the interplay between clonal reproduction and disturbance. Evolution 52, 379-393. doi:10.2307/2411075

Edmunds, P. J., and Gates, R. D. (2003). Has coral bleaching delayed our understanding of fundamental aspects of coral-dinoflagellate symbioses? Bioscience 53, 976-980. doi:10.1641/0006-3568(2003)053[0976: $\mathrm{HCBDOU}] 2.0 . \mathrm{CO} ; 2$
Faircloth, B. C. (2006). GMCONVERT: file conversion for GENEMAPPER output files. Molecular Ecology Notes 6, 968-970. doi:10.1111/J.14718286.2006.01419.X

Garcia Reyes, J., and Schizas, N. V. (2010). No two reefs are created equal: fine-scale population structure in the threatened coral species Acropora palmata and A. cervicornis. Aquatic Biology 10, 69-83. doi:10.3354/ AB00254

Gladfelter, E. H. (1982). Skeletal development in Acropora cervicornis: I. Patterns of calcium carbonate accretion in the axial corallite. Coral Reefs 1, 45-51. doi:10.1007/BF00286539

Honnay, O., and Bossuyt, B. (2005). Prolonged clonal growth: escape route or route to extinction? Oikos 108, 427-432. doi:10.1111/J.0030-1299. 2005.13569.X

Mège, P., Schizas, N. V., Garcia Reyes, J., and Hrbek, T. (2014). Genetic seascape of the threatened Caribbean elkhorn coral, Acropora palmata, on the Puerto Rico Shelf. Marine Ecology. [Published online early 11 February 2014]. doi:10.1111/MAEC.12135

Meirmans, P. G., and van Tienderen, P. H. (2004). GENOTYPE and GENODIVE: two programs for the analysis of genetic diversity of asexual organisms. Molecular Ecology Notes 4, 792-794. doi:10.1111/ J.1471-8286.2004.00770.X

Miller, W. J., Muller, E. M., Rogers, C. S., Waara, R., Atkinson, A., Whelan, K. R. T., Patterson, M., and Witcher, B. (2009). Coral disease following massive bleaching in 2005 causes $60 \%$ decline in coral cover on reefs in the US Virgin Islands. Coral Reefs 28, 925-937. doi:10.1007/S00338009-0531-7

Precht, W. F., Bruckner, A. W., Aronson, R. B., and Bruckner, R. J. (2002). Endangered acroporid corals of the Caribbean. Coral Reefs 21, 41-42. doi:10.1007/S00338-001-0209-2

Raymond, M., and Rousset, F. (1995). GENEPOP (Version 1.2): population genetics software for exact tests and ecumenicism. The Journal of Heredity 86, 248-249.

Reusch, T. B. H., Ehlers, A., Hämmerli, A., and Worm, B. (2005). Ecosystem recovery after climatic extremes enhanced by genotypic diversity. Proceedings of the National Academy of Sciences of the United States of America 102, 2826-2831. doi:10.1073/PNAS.0500008102

Tunnicliffe, V. (1981). Breakage and propagation of the stony coral Acropora cervicornis. Proceedings of the National Academy of Sciences of the United States of America 78, 2427-2431. doi:10.1073/PNAS.78. 4.2427

Van Oppen, M. J. H., Willis, B. L., van Vugt, H. W. J. A., and Miller, D. J. (2000). Examination of species boundaries in the Acropora cervicornis group (Scleractinia, Cnidaria) using nuclear DNA sequence analyses. Molecular Ecology 9, 1363-1373. doi:10.1046/J.1365-294X.2000. 01010.X

Van Oppen, M. J. H., Souter, P., Howells, E. J., Heyward, A. J., and Berkelmans, R. (2011). Novel genetic diversity through somatic mutations: fuel for adaptation of reef corals? Diversity 3, 405-423. doi:10.3390/D3030405

Vollmer, S. V., and Palumbi, S. R. (2002). Hybridization and the evolution of reef coral diversity. Science 296, 2023-2025. doi:10.1126/SCIENCE. 1069524

Weir, B. S., and Cockerham, C. C. (1984). Estimating F-statistics for the analysis of population structure. Evolution 38, 1358-1370. doi:10.2307/ 2408641

Williams, D. E., and Miller, M. W. (2005). Coral disease outbreak: pattern, prevalence and transmission in Acropora cervicornis. Marine Ecology Progress Series 301, 119-128. doi:10.3354/MEPS301119 